\title{
Chosen Vascular Risk Markers in Pseudoexfoliation Syndrome: An Age-Related Disorder
}

\author{
Hanna Lesiewska, ${ }^{1}$ Agnieszka Lukaszewska-Smyk, ${ }^{1}$ Grażyna Odrowąż-Sypniewska, ${ }^{2}$ \\ Magdalena Krintus, ${ }^{2}$ Aneta Mańkowska-Cyl, ${ }^{2}$ and Grażyna Malukiewicz ${ }^{1}$ \\ ${ }^{1}$ Department of Ophthalmology, The Nicolaus Copernicus University, Ludwik Rydygier's Collegium Medicum, Bydgoszcz, Poland \\ ${ }^{2}$ Department of Laboratory Medicine, The Nicolaus Copernicus University, Ludwik Rydygier's Collegium Medicum, \\ Bydgoszcz, Poland \\ Correspondence should be addressed to Hanna Lesiewska; hanjot@op.pl
}

Received 23 April 2017; Accepted 11 October 2017; Published 31 October 2017

Academic Editor: Alejandro Cerviño

Copyright (c) 2017 Hanna Lesiewska et al. This is an open access article distributed under the Creative Commons Attribution License, which permits unrestricted use, distribution, and reproduction in any medium, provided the original work is properly cited.

Purpose. To evaluate lipids and C-reactive protein serum levels in patients with pseudoexfoliation syndrome (PEX) in the Polish population. Methods. 96 patients were studied with PEX and 79 control subjects. Total cholesterol, triglycerides, high-density lipoprotein (HDL)-cholesterol, low-density lipoprotein (LDL)-cholesterol, non-HDL-cholesterol and CRP serum levels, and TG/HDL-C and TC/HDL-C indexes were assessed. Results. There were no significant differences in concentration of lipids and values of TC/HDL-C, TG/HDL-C, and non-HDL-C between PEX and control groups. High-sensitivity C-reactive protein was not increased in patients with PEX. Conclusions. Our results cast doubt on the opinion on the possible PEX and vascular diseases relation. Further studies on this subject are mandatory.

\section{Introduction}

Pseudoexfoliation syndrome (PEX) is an age-related complex systemic disorder of the extracellular matrix affecting the eye and visceral organs. The average worldwide prevalence of PEX is $10 \%-20 \%$ of the general population over the age of 60 years $[1,2]$. A population-based study in the Northeastern USA found prevalence of $0.67 \%$ in people aged $52-64$ years, $2.6 \%$ in people aged $65-74$ years, and $5 \%$ in people aged $78-85$ years. In a survey conducted in Iceland, the prevalence of PEX increased from $2.5 \%$ in the patients aged $50-59$ years to $40.6 \%$ in those aged $>80$ years [3].

Originally, PEX was thought to be limited to the anterior segment of the eye; some studies have indicated, however, that pseudoexfoliative material may be present in blood vessels and impaired endothelial function can be observed $[1,2]$. Since endothelial dysfunction is an independent predictor of future cardiovascular and cerebrovascular events, it might suggest an increased vascular risk in PEX patients [4-6]. Dyslipidemia is a well-established risk factor for cardiovascular and cerebrovascular diseases. Many studies have shown a strong correlation between serum lipids levels and risk of developing vascular events [6-8]. It was found that C-reactive protein (CRP) is significantly associated with cardiovascular disease [9].

The relationship between PEX and vascular diseases has been investigated in many studies [10-16]. Some authors have observed a connection between PEX and cardiovascular or cerebrovascular diseases $[4,10-12,14,15]$. However, there are also studies reporting that PEX is not associated with arterial hypertension, ischemic heart disease, and cerebrovascular diseases [2, 17-21]. This discrepancy in opinions gave us a spur to assess the relation between PEX syndrome and chosen vascular risk markers in the Polish population.

\section{Material and Methods}

The subjects for this study were recruited from patients who presented to the Department of Ophthalmology, Collegium Medicum, UMK in Bydgoszcz, Poland for cataract surgery. Exclusion criteria were any other ocular diseases except PEX and cataract. Pseudoexfoliation changes were identified 
by slit lamp examination after pupil dilation as the presence of typical PEX material on the anterior lens surface, iris, or corneal endothelium in either eye. The individuals without any evidence of pseudoexfoliation deposits were taken as the control group. This study has been approved by the local bioethical committee. All patients gave their informed consent for this study.

We followed the methods described in our previous study [22]. Blood samples were collected in all patients after an overnight fast. Plasma was obtained within less than 1 hour to avoid proteolysis and stored deep-frozen $\left(-80^{\circ} \mathrm{C}\right)$ in small aliquots until assayed but no longer than 8 months. Total cholesterol (TC), high-density lipoprotein (HDL)-cholesterol, and triglyceride (TG) levels were measured by an autoanalyzer (ARCHITECT ci8200, Abbott Diagnostics, Wiesbaden, Germany) using enzymatic methods. Low-density lipoprotein (LDL)-cholesterol levels were calculated using the Friedewald formula. Moreover, TG/HDL-C, TC/HDL-C, and nonHDL-C as atherogenic indexes were calculated. Highsensitivity CRP (hs-CRP) level was measured using the BN II System nephelometer (High-Sensitivity CRP; Siemens Healthcare Diagnostics, Deerfield, IL, USA), providing excellent precision with the coefficient of variation $(\mathrm{CV})$ reported by the manufacturer of less than $10 \%$. CVs for hs-CRP estimated in our laboratory were below 3.5\% and below $4.5 \%$ for hs-CRP concentrations below $1 \mathrm{mg} / \mathrm{L}$ and above $3 \mathrm{mg} / \mathrm{L}$, respectively. The lower limit of hs-CRP detection was $0.175 \mathrm{mg} / \mathrm{L}$. We divided the patients with PEX into three groups: group A with low risk (hs-CRP concentration less than $1.0 \mathrm{mg} / \mathrm{L}$ ), group B with average risk (hs-CRP concentration 1.0 to $3.0 \mathrm{mg} / \mathrm{L}$ ), and group $\mathrm{C}$ with high risk of cardiovascular disease (hs-CRP concentration above $3.0 \mathrm{mg} / \mathrm{L}$ ) according to the American Heart Association and U.S. Centers for Disease Control and Prevention.

The statistical analysis of results was performed using the Kolmogorov-Smirnov test to assess normality of distribution of investigated parameters. Data were expressed as medians with the interquartile range (25th-75th percentiles) according to the distributions of the continuous variables. Differences between the PEX and control groups were analyzed by the Mann-Whitney $U$ test for independent samples of nonparametric data. Comparisons of median values between groups were done by ANOVA. The significance level for all statistical tests was 0.05 . Statistical analysis was performed using Statistica software (version 8).

\section{Results}

We studied 96 patients with PEX (26 males and 70 females), median age 76 years $\left(Q_{1}=72 ; Q_{3}=82\right)$, and 79 age- and sexmatched controls (28 males and 51 females), median age 75 years $\left(Q_{1}=70 ; Q_{3}=80\right)$. The concentrations of serum lipids, hs-CRP, and values of atherogenic indexes constituting one of the major cardiovascular risk factors are shown in Table 1 . There were no significant differences in concentration of lipids between PEX and control groups. Moreover, we did not observe significant differences for other calculated parameters like TC/HDL-C, TG/HDL-C, and non-HDL-C. High-sensitivity C-reactive protein level was not increased
TABLE 1: Biochemical parameters in PEX patients and controls.

\begin{tabular}{lccc}
\hline Parametres & $\begin{array}{c}\text { PEX patients' } \\
\text { median }\left(\mathrm{Q}_{1}-\mathrm{Q}_{3}\right) \\
n=96\end{array}$ & $\begin{array}{c}\text { Control median } \\
\left(\mathrm{Q}_{1}-\mathrm{Q}_{3}\right) \\
n=79\end{array}$ & $p$ \\
\hline TC $(\mathrm{mg} / \mathrm{dL})$ & $199(176-240)$ & $213(178-245)$ & 0.25 \\
HDL-C $(\mathrm{mg} / \mathrm{dL})$ & $55(45-66)$ & $53(46-64)$ & 0.39 \\
TG $(\mathrm{mg} / \mathrm{dL})$ & $125.5(83.5-161.5)$ & $114(88-152)$ & 0.61 \\
LDL-C $(\mathrm{mg} / \mathrm{dL})$ & $114.5(93.5-152)$ & $128(103-156)$ & 0.14 \\
Non-HDL-C $(\mathrm{mg} / \mathrm{dL})$ & $139(115.5-181)$ & $158(128-193)$ & 0.13 \\
TC/HDL-C & $3.73(2.95-4.50)$ & $3.78(3.28-4.54)$ & 0.26 \\
TG/HDL-C & $2.2(1.39-3.30)$ & $2.07(1.45-3.45)$ & 0.83 \\
hs-CRP mg/l & $1.53(0.75-3.71)$ & $1.57(0.74-3.44)$ & 0.90 \\
\hline
\end{tabular}

in patients with PEX and was found to be similar to that of controls.

The HDL-C concentration in the PEX female subgroup was statistically higher than in males: $58 \mathrm{mg} / \mathrm{dL}\left(\mathrm{Q}_{1}: 48\right.$; $\left.\mathrm{Q}_{3}: 67\right)$ versus $52 \mathrm{mg} / \mathrm{dL}\left(\mathrm{Q}_{1}: 40 ; \mathrm{Q}_{3}: 58\right), p=0.02$. In the control group, we did not find such correlation. The concentrations of other serum lipids, hs-CRP, and values of atherogenic indexes did not differ between males and females, both in PEX and control groups.

We did not observe any significant differences for lipids and atherogenic indexes between the following subgroups: group A with low risk, group B with average risk, and group $\mathrm{C}$ with high risk of cardiovascular disease (Table 2).

\section{Discussion}

There are some studies on the possible association between PEX and vascular diseases although their results are inconclusive [10-16]. The risk for cardiovascular and cerebrovascular diseases might be ascribed to the accumulation of pseudoexfoliative fibrils in the arterial wall [2].

It has been proven that one of the several tests in a vascular risk profile, along with tests for cholesterol and triglycerides, is high-sensitivity CRP [6-9].

Studies, that analyzed serum lipids levels and PEX association, provided conflicting results. All these studies are difficult to compare as they vary in size and design. Türkyılmaz et al. found that the mean total cholesterol and triglycerides levels were significantly higher, and mean serum HDL level was lower in the PEX group of 40 patients compared to the controls [23]. We were unable to show an association between the serum lipid levels and PEX syndrome. Our findings are in accordance with the results of Atalar et al. (23 PEX patients) and Spečkauskas et al. (152 PEX patients), who did not reveal the differences in lipid levels in PEX patients $[2,24]$. The latter authors found no clear PEX association with triglyceride and HDL cholesterol levels as well as ischemic heart disease after controlling for effect of age in the population-based study. Presence of PEX was not significantly associated with the blood concentration of high-density lipoproteins and cholesterol in the study of Jonas et al. comprising 69 PEX patients [25].

There is also discrepancy regarding CRP levels in PEX. Elevated plasma hs-CRP levels have been reported in patients 
TABLE 2: Lipid concentration and atherogenic indexes in relation to hs-CRP levels in patients with PEX.

\begin{tabular}{|c|c|c|c|c|}
\hline & $\begin{array}{c}\text { Group A median }\left(\mathrm{Q}_{1}-\mathrm{Q}_{3}\right) \\
n=34\end{array}$ & $\begin{array}{l}\text { Group B median (Q1-Q3) } \\
n=35\end{array}$ & $\begin{array}{l}\text { Group C median (Q1-Q3) } \\
n=27\end{array}$ & $p$ \\
\hline $\mathrm{TC}(\mathrm{mg} / \mathrm{dL})$ & $200(182-245)$ & $190(164-217)$ & $204(161-244)$ & $\overline{0.18}$ \\
\hline TG (mg/dL) & $114(83-181)$ & $115(81-148)$ & $130(114-156)$ & 0.95 \\
\hline HDL-C (mg/dL) & $59(48-68)$ & $54(45-66)$ & $51(44-58)$ & 0.35 \\
\hline LDL-C (mg/dL) & $115(95-152)$ & $104(92-142)$ & $130(98-161)$ & 0.24 \\
\hline non-HDL-C (mg/dL) & $154(127-190)$ & $126(115-172)$ & $157(118-191)$ & 0.26 \\
\hline TC/HDL-C & $3.9(3.4-4.5)$ & $3.3(2.7-4.8)$ & $4.1(3.2-4.8)$ & 0.63 \\
\hline TG/HDL-C & $2.1(1.4-3.4)$ & $2.2(1.5-3.1)$ & $2.6(1.7-3.5)$ & 0.70 \\
\hline
\end{tabular}

with PEX by Sorkhabi et al. [26]. Nevertheless, the study of Kymionis et al. as well as Yüksel et al. revealed that serum CRP levels were not elevated in patients with PEX $[27,28]$. This is in accordance with our results which showed that serum CRP levels were not increased in patients with PEX and were found to be similar to that of controls. The conflicting results of these studies may be due to the selection bias. Similarly to Sorkhabi et al., in our study, we strictly excluded all conditions which may affect the levels of inflammatory biomarkers [26].

Our research casts doubt on the possibility of PEX and cardiovascular and cerebrovascular disease association. These findings suggest that patients with this syndrome do not suffer from increased comorbidity and mortality.

\section{Conclusions}

Serum lipids and hs-CRP levels nor values of atherogenic index hs-CRP were elevated in PEX patients in the Polish population. These findings raise doubt on the opinion on the possible PEX and vascular disease relation. As ours and other studies results are inconclusive, the causes and connections of PEX still remain unexplained and further studies on this subject are required.

\section{Conflicts of Interest}

The authors declare that they have no conflicts of interest.

\section{References}

[1] S. Schumacher, U. Schlötzer-Schrehardt, P. Martus, W. Lang, and G. O. Naumann, "Pseudoexfoliation syndrome and aneurysms of the abdominal aorta," The Lancet, vol. 357, no. 9253, pp. 359-360, 2001.

[2] P. T. Atalar, E. Atalar, H. Kilic et al., "Impaired systemic endothelial function in patients with pseudoexfoliation syndrome," International Heart Journal, vol. 47, no. 1, pp. 77-84, 2006.

[3] A. Tarkkanen, "Is exfoliation syndrome a sign of systemic vascular disease?," Acta Ophthalmologica, vol. 86, no. 8, pp. 832-836, 2008.

[4] P. Mitchell, J. J. Wang, and W. Smith, "Association of pseudoexfoliation syndrome with increased vascular risk," American Journal of Ophthalmology, vol. 124, no. 5, pp. 685$687,1997$.

[5] T. Neunteufl, S. Heher, R. Katzenschlager et al., "Late prognostic value of flow-mediated dilation in the brachial artery of patients with chest pain," The American Journal of Cardiology, vol. 86, no. 2, pp. 207-210, 2000.

[6] V. Schachinger, M. B. Britten, and A. M. Zeiher, "Prognostic impact of coronary vasodilator dysfunction on adverse longterm outcome of coronary heart disease," Circulation, vol. 101, no. 16, pp. 1899-1906, 2000.

[7] I. H. Yusuf, "Pseudoexfoliation syndrome and cardiovascular disease: studies must control for all cardiovascular risk factors," Eye, vol. 27, no. 11, pp. 1328-1329, 2013.

[8] H. Liu and J. Li, "Aging and dyslipidemia: a review of potential mechanisms," Ageing Research Reviews, vol. 19, pp. 43-52, 2015.

[9] E. Coffman and J. Richmond-Bryant, "Multiple biomarker models for improved risk estimation of specific cardiovascular diseases related to metabolic syndrome: a cross-sectional study," Population Health Metrics, vol. 13, no. 7, 2015.

[10] J. S. Ritland, K. Egge, S. Lydersen, R. Juul, and S. O. Semb, "Exfoliative glaucoma and primary open-angle glaucoma: associations with death causes and comorbidity," Acta Ophthalmologica Scandinavica, vol. 82, no. 4, pp. 401-404, 2004.

[11] C. Akarsu and B. Unal, "Cerebral haemodynamics in patients with pseudoexfoliation glaucoma," Eye, vol. 19, no. 12, pp. 1297-1300, 2005.

[12] L. Bojic, R. Ermacora, S. Polic et al., "Pseudoexfoliation syndrome and asymptomatic myocardial dysfunction," Graefe's Archive for Clinical and Experimental Ophthalmology, vol. 243, no. 5, pp. 446-449, 2005.

[13] N. Yüksel, Y. Anik, O. Altintaş, I. Onur, Y. Cağlar, and A. Demirci, "Magnetic resonance imaging of the brain in patients with pseudoexfoliation syndrome and glaucoma," Ophthalmologica, vol. 220, no. 2, pp. 125-130, 2006.

[14] M. Citirik, G. Acaroglu, C. Batman, L. Yildiran, and O. Zilelioglu, "A possible link between the pseudoexfoliation syndrome and coronary artery disease," Eye, vol. 21, no. 1, pp. 11-15, 2007.

[15] M. R. Praveen, S. K. Shah, A. R. Vasavada et al., "Pseudoexfoliation as a risk factor for peripheral vascular disease: a case-control study," Eye, vol. 25, no. 2, pp. 174-179, 2011.

[16] K. A. Gonen, T. Gonen, and B. Gumus, "Renal artery stenosis and abdominal aorta aneurysm in patients with pseudoexfoliation syndrome," Eye, vol. 27, no. 6, pp. 735-741, 2013.

[17] A. Ringvold, S. Blika, and L. Sandvik, "Pseudo-exfoliation and mortality," Acta Ophthalmologica Scandinavica, vol. 75, no. 3, pp. 255-256, 1997.

[18] K. R. Shrum, M. G. Hattenhauer, and D. Hodge, "Cardiovascular and cerebrovascular mortality associated with ocular 
pseudoexfoliation," American Journal of Ophthalmology, vol. 129, no. 1, pp. 83-86, 2000.

[19] R. Allingham, M. Loftsdottir, M. S. Gottfredsdottir et al., "Pseudoexfoliation syndrome in Icelandic families," British Journal of Ophthalmology, vol. 85, no. 6, pp. 702-707, 2001.

[20] B. J. Shingleton, J. Heltzer, and M. W. O'Donoghue, "Outcomes of phacoemulsification in patients with and without pseudoexfoliation syndrome," Journal of Cataract \& Refractive Surgery, vol. 29, no. 6, pp. 1080-1086, 2003.

[21] A. Tarkkanen, A. Reunanen, and T. Kivelä, "Frequency of systemic vascular diseases in patients with primary open-angle glaucoma and exfoliation glaucoma," Acta Ophthalmologica, vol. 86, no. 6, pp. 598-602, 2008.

[22] H. Lesiewska, G. Malukiewicz, A. Mańkowska-Cyl, and G. Odrowąż-Sypniewska, "Lipids and C-reactive protein as vascular risk markers in pseudoexfoliation syndrome," Acta Ophthalmologica, vol. 94, no. 5, pp. e380-e381, 2016.

[23] K. Türkyılmaz, V. Oner, A. Kırbas et al., "Serum YKL-40 levels as a novel marker of inflammation and endothelial dysfunction in patients with pseudoexfoliation syndrome," Eye, vol. 27, no. 7, pp. 854-859, 2013.

[24] M. Spečkauskas, A. Tamošiūnas, and V. Jašinskas, “Association of ocular pseudoexfoliation syndrome with ischaemic heart disease, arterial hypertension and diabetes mellitus," Acta Ophthalmologica, vol. 90, no. 6, pp. e470-e475, 2012.

[25] J. B. Jonas, V. Nangia, A. Matin et al., "Pseudoexfoliation: normative data and associations. The Central India Eye and Medical Study," PLoS One, vol. 8, no. 10, article e76770, 2013.

[26] R. Sorkhabi, A. Ghorbanihaghjo, M. Ahoor, M. Nahaei, and N. Rashtchizadeh, "High-sensitivity C-reactive protein and tumor necrosis factor alpha in pseudoexfoliation syndrome," Oman Medical Journal, vol. 28, no. 1, pp. 16-19, 2013.

[27] G. D. Kymionis, V. P. VP Kankariya, and G. A. Kontadakis, "Serum C-reactive protein levels in exfoliation syndrome and exfoliative glaucoma," Eye, vol. 25, no. 10, pp. 1383-1384, 2011.

[28] N. Yüksel, D. Pirhan, O. Altintaş, and Y. Cağlar, "Systemic high-sensitivity C-reactive protein level in pseudoexfoliation syndrome and pseudoexfoliation glaucoma," Journal of Glaucoma, vol. 19, no. 6, pp. 373-376, 2010. 


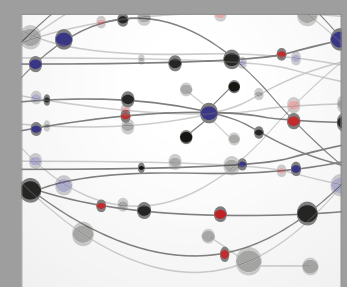

The Scientific World Journal
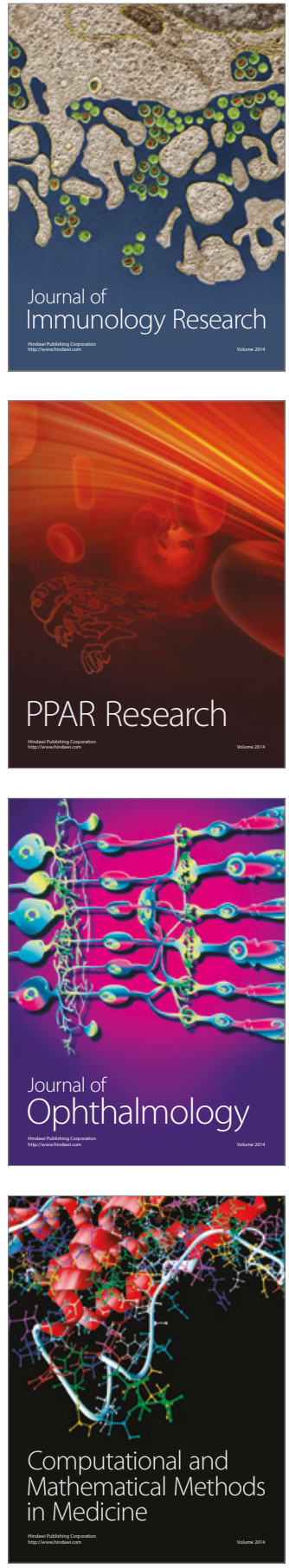

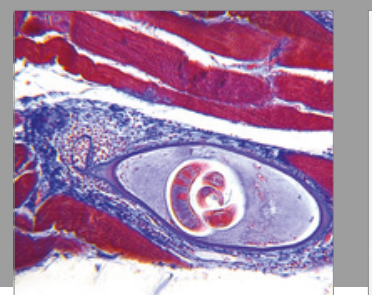

Gastroenterology Research and Practice
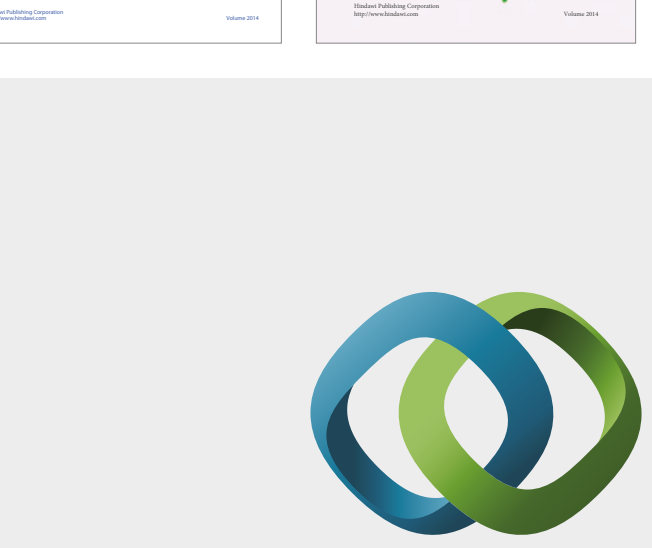

\section{Hindawi}

Submit your manuscripts at

https://www.hindawi.com
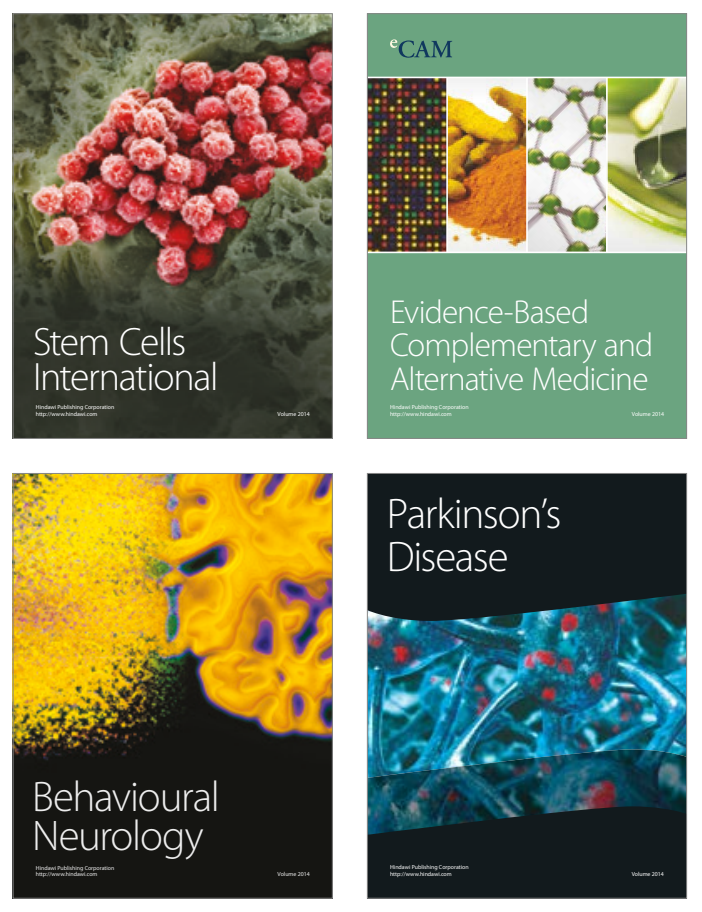
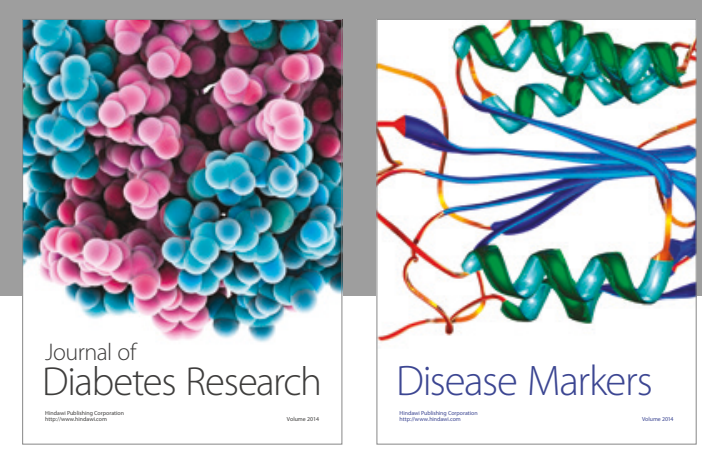

Disease Markers
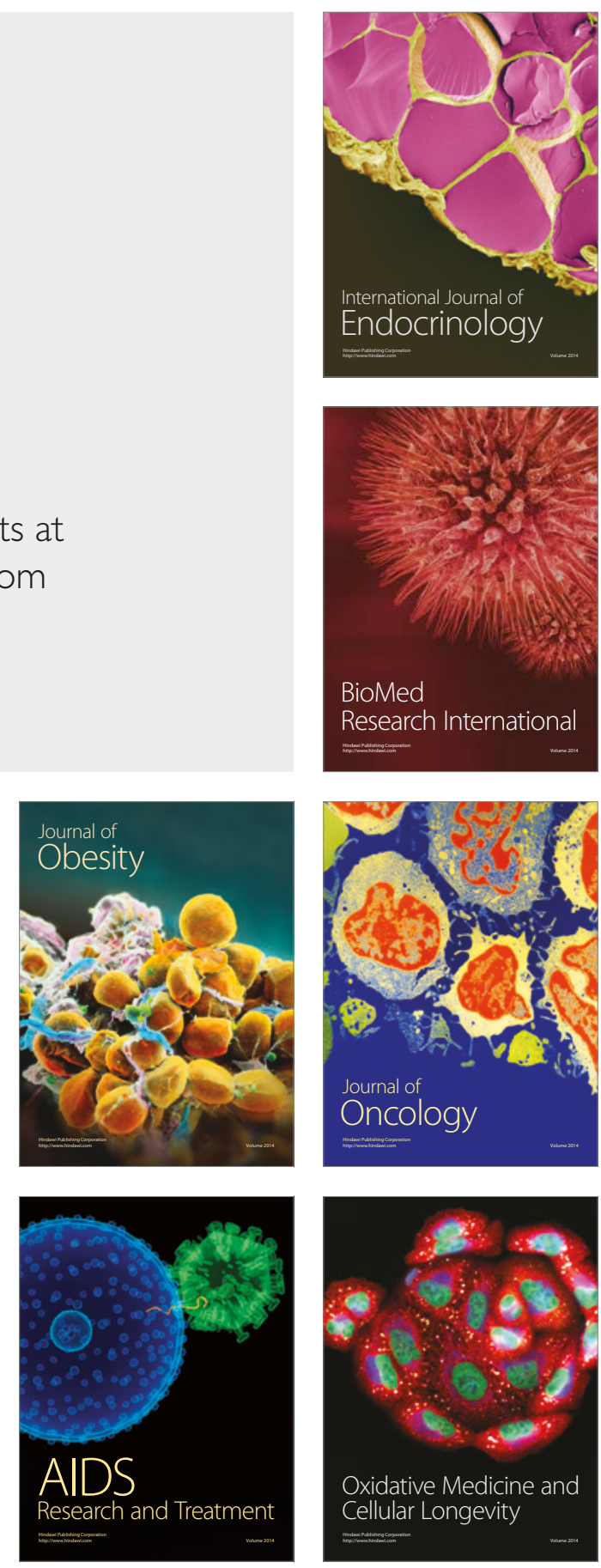